\title{
An Integrative Approach to Spirituality Based on Attachment
}

Hatun Sevgi-Yalın ${ }^{1}$

"Buddha's Mom: The Neurobiology of Spiritual Awakening"

Vincent Schroder, Philadelphia, 2017, Elsevier, p. 390

The human soul, or psyche, is a subject upon which many things have been said in an attempt to understand it. Religion and science are considered to be the two main and opposing authorities for its explanation. However, questions about the true nature of the psyche still remain. In the last few decades, research has followed a new path where religion and science have met and become friends rather than opponents. Vincent Schroder's book, Buddha's Mom: The Neurobiology of Spiritual Awakening, converges science and spirituality by examining Buddha's psycho-spiritual inheritance through attachment. The book aims to explore the possible picture "before enlightenment" in a way that is both scientifically solid and spiritually sound.

Schroder completed his doctorate in the field of clinical psychology and has two master's degrees, one in clinical psychology and another in counseling. He received his degree in America and has spent most of his career in Hawaii and Florida, with some studies conducted in Thailand. Currently, he works as a psychologist and adjunct professor.

The book consists of nine chapters. Chapter 1 aims to uncover all the distinguishable early-life influences of Siddhartha Gautama, who later became Buddha. Two

1 Correspondence to: Hatun Sevgi-Yalın is a PhD student at Marmara University in the Psychological Counseling and Guidance Department. Her interest areas include gifted education, couple and family psychotherapies, and spiritual counseling. Email: hatunsevgiyalin@gmail.com

Citation: Sevgi-Yalın, H. (2017). An integrative approach to spirituality based on attachment [Buddha's Mom: The Neurobiology of Spiritual Awakening book review V. Schroder]. Spiritual Psychology and Counseling, 2, 225-228. http://dx.doi.org/10.12738/spc.2017.2.0022R 
attachments are focused upon: one is the maternal/biological attachment, mainly studied by John Bowlby, and the other is Buddhism's major tenet where Buddha declares attachment as the source of human suffering. In the next three chapters, the concept of attachment is viewed through different lenses, such as Ken Wilber's integrative model and main terms. Chapter 5 is about Buddha's stepmother, Prajapati, who played significant role in Buddha's early life and potential for his enlightenment. Through her, the feminine principle is reviewed and deeply examined for its importance in the human psyche and sentience. In the following two chapters, the wounds of attachment and their manifestations are explained. Through to the end of the book, consistencies among spiritual heritages, evolution, and neuroscience are shown (based on biotensegrity, polyvagal theory, and somatic psychotherapies) through certain schools of Buddhism.

In the 1960s, John Bowlby (2005) performed groundbreaking research on attachment, demonstrating how early life experiences (especially the mother-baby relationship) have tremendous implications on development over one's life span and enormous power in shaping the personality (self/ego/mind).He scientifically studied how once a baby establishes a certain attachment style with a caregiver, the pattern repeatedly follows into adulthood. Schroder gives wide space to attachment theory, examining Buddha's life from Bowlby's perspective. In the case of Siddhartha Gautama, he was born in wealth and treated with an abundance of love. He had strong love-based relations with his extended family, including his friends and wife. But at some point in his life, he decided to leave all that behind, struggling to free himself from both materialistic and emotional attachments. He looked for meaning, a spiritual truth, and finally reached the realization that being attached, clingy, and longing causes human suffering.

How distinct from the attachment discovered by Bowlby is that identified by Buddha; how much do they overlap? On this point, the author invites readers to look at these two attachments through specific lenses, such as Ken Wilber's (2000) integral model and certain key concepts that move one toward a marriage of two attachments (pp. 46, 74, 75). Even though these two attachments remained separate throughout the years, Schroder discusses this distinction through the concepts of "relative attachment" (p. 64) and "relative love" (p. 69), merging them in a way where they both have their place in human functioning.

After reaching an integrated approach to attachment, the author focuses on Siddhartha's biography, especially on his relationship with his stepmother, in order to show this bridge. Embodying both sides of attachment, his stepmother both protected and released him. Through her, Schroder puts emphasis on the feminine principle (pp. 34, 59). He discusses how a lack of integration of the feminine principle leads to oppression and misalignments, and how this principle turns out to be the key for 
humans to reach their ultimate. Additionally, what Siddhartha found after leaving home and six years of searching was also integration, a Middle Way defined as neither over-attachment nor over-detachment.

From this point, the author turns to the biological territory and points out the importance of early life attachment on one's spiritual journey. As the body of attachment research shows, maternal attachment shapes all kinds of relations, including body, emotion, feeling, self, others, work, values, and spirituality. Also, the wounds of attachment damage emotional growth and directly contribute to suffering in the form of self-blame (p. 213), de-realization (p. 214), feeling insufficient (p. 216), self-harm (p. 217), being a problem child (p. 219), and meaninglessness (p. 221). Therefore, the healthier one's attachments, the greater the potential Buddhism has to light the way.

Toward the end of the book, Schroder points out how integral the perspective to attachment is manifested, both in certain Buddhist schools and in the research findings of neuroscience, evolution, and clinical psychology. Practices in Vajrayana and Tantric Buddhism combine the body and spirit in a way that aim for nonattachment by repurposing every manner of attachment. Jaak Panksepp's (2004) work in the field of affective neuroscience and studies in biotensegrity (p. 331), polyvagal theory (p. 337), and somatic therapies (p. 339) show the fuel behind the spiritual journey, also indicating how the depth of being human is somatic. As the evidence shows, the potential for spiritual growth and realization comes through attachment. One liberates from attachment through attachment.

In conclusion, Buddha's Mom provides a model in which science and spirituality together offer an integrative approach to human functioning. The author shows this integration with attachment through Buddha's biography, Buddhist teachings, and scientific findings in neuroscience, evolution, and clinical psychology. Through many important and inter-related ideas and research findings from different fields, "two attachments" reach an integrative perspective. This integrative lens also allows one to see how many of history's respectable teachers, poets, philosophers, and prophets share common ground with scientific findings and Buddhist teachings. Schroder offers a novel model that provides a framework and inspiration for future studies and applications on spirituality and psychology/psychotherapy integration. As such, this work can contribute to the theoretical foundation needed for developing spiritualoriented interventions in the field of psychotherapy. By pointing out the importance of early attachment experiences on spirituality, paradoxes, and pity teachings, this work can also help construct the contents of such interventions. The book is so rich in terms of concepts and theories. However, a more organized presentation of this voluminous knowledge will help readers follow and comprehend better. This need for presentation is considerably expected in future editions of the book or in future studies. 


\section{References}

Bowlby, J. (2005). A secure base: Clinical applications of attachment theory (Vol. 393). London, UK: Routledge.

Panksepp, J. (2004). Affective neuroscience: The foundations of human and animal emotions. New York, NY: Oxford University Press.

Wilber, K. (2000). Integral psychology: Consciousness, spirit, psychology. Boston, MA: Shambhala Publications. 